\title{
Investigation of Cathodoluminescence of Hydrated Fluorescent Stained Platelets Using an SEM
}

\author{
N. Erdman ${ }^{*}$, C.H. Nielsen ${ }^{*}$ and C.A. Ackerley ${ }^{* *}$ \\ * JEOL USA, 11 Dearborn Rd., Peabody, MA 01960 \\ ** Department of Pediatric Laboratory Medicine, Hospital for Sick Children, 555 University Ave., \\ Toronto, ON, Canada. M5G1X8
}

The development of chambers capable of maintaining specimens in a hydrated environment while being examined under the SEM has been previously reported by Thiberge et al [1]. The work described a system whereby a light pipe placed at the bottom of the sample collected light generated by electron beam interaction with the specimen and delivered it to a photomultiplier. Using this approach Thiberge et al were able to synchronously detect backscatter electrons (BE) and cathodoluminescence (CL) on fixed cells containing lipid droplets, which provided the major constituent of the emitted light. No attempts were made to detect CL signal from fluorescent stains.

A major goal in our laboratories has been to develop methods for serial imaging of live cells using a similar chamber to that described by Thiberge et al, only we are using a much more electron lucent partition membrane comprised of silicon oxide [2]. We were not only able to image live cultured cells, but now are able to observe live immunogold labeled cells serially with an $85 \%$ post electron beam exposure cell viability using low dose backscatter imaging techniques [3]. A major drawback to this technique is the inability to identify any internal ultrastructure. Any internal immunolabeling techniques or the use of any heavy metal stains would kill the cells. We then looked at several conventionally fixed GFP transfected cell lines which had been either critical point dried and rendered conductive with a thin layer of carbon or grown in the chambers with the silicon oxide partition membrane. We examined these cells in an SEM equipped with both a CL detector and a BE detector. Much to our surprise, we were only able to detect GFP signal and external cell morphology in the cells, which were fully hydrated. Subsequent investigations employing standard immunofluorescent staining techniques confirmed that commonly employed fluorescent stains such as FITC, Rhodamine, Texas Red and Oregon Green all were detected when the cells were hydrated using CL.

In order to further verify this phenomenon, we opted to study platelets which had been stained with mepacrine. Mepacrine specifically stains platelet dense granules and fluoresces at a wavelength of $478 \mathrm{~nm}$ [4]. Dense granules are involved in normal platelet coagulation. In some bleeding disorders, dense granule numbers are lower and they are implicated in the formation of atherosclerotic plaques [5]. A major advantage to using platelets is they readily adhere to the partition membrane and are relatively thin in inactivated state. Platelet-rich plasma from normal individuals containing $5 \times 10^{-5}$ $\mathrm{mol} / \mathrm{L}$ mepacrine was incubated for 30 minutes at $37^{\circ} \mathrm{C}$. Platelets were harvested by centrifugation at $1,000 \mathrm{~g}$ for ten minutes, washed twice with Tyrode's calcium-free solution, and resuspended in Tyrode's solution at a concentration of $5 \times 10^{8}$ cells $/ \mathrm{ml}$. A drop of platelet suspension was then placed on the partition membrane for 10 minutes. Controls included platelets which weren't exposed to mepacrine. The chamber was then filled with the same solution and sealed. It was then transferred to the SEM where the chamber was maintained at a temperature of $37^{\circ} \mathrm{C}$. Images from both the $\mathrm{BE}$ and CL detector were obtained using a scan time of 30 seconds. 
Dense granules were easily detected using both BE and CL imaging (Fig.1, 2). Dense granules in platelets are known to be rich in $\mathrm{K}$ and $\mathrm{Ca}$ hence their detection in $\mathrm{BE}$ images. In $\mathrm{CL}$ images the dense granules and only part of the cytoplasm were visible.

Platelets possess numerous surface receptors which can easily be immunogold labeled. As a principal player in clot formation, the relationship between dense granules and surface epitopes implicated in coagulation using this technique with serial imaging will further elucidate the comprehension of this cell to cell interaction.

\section{Reference}

[1] S. Thiberge et al., PNAS. 101(10) (2004) 3346.

[2] C.A. Ackerley et al., Microsc. Microanal. 12 (Suppl 2) (2006) 428CD

[3] C.A. Ackerley and C.H. Nielsen. Proc Eighth Multinational Cong on Microsc (2007) 343.

[4] M. Reddington et al., Blood. 89 (5) (1989) 1300.

[5] L. Olcay et al., J Clin Pathol 58 (2005) 939.
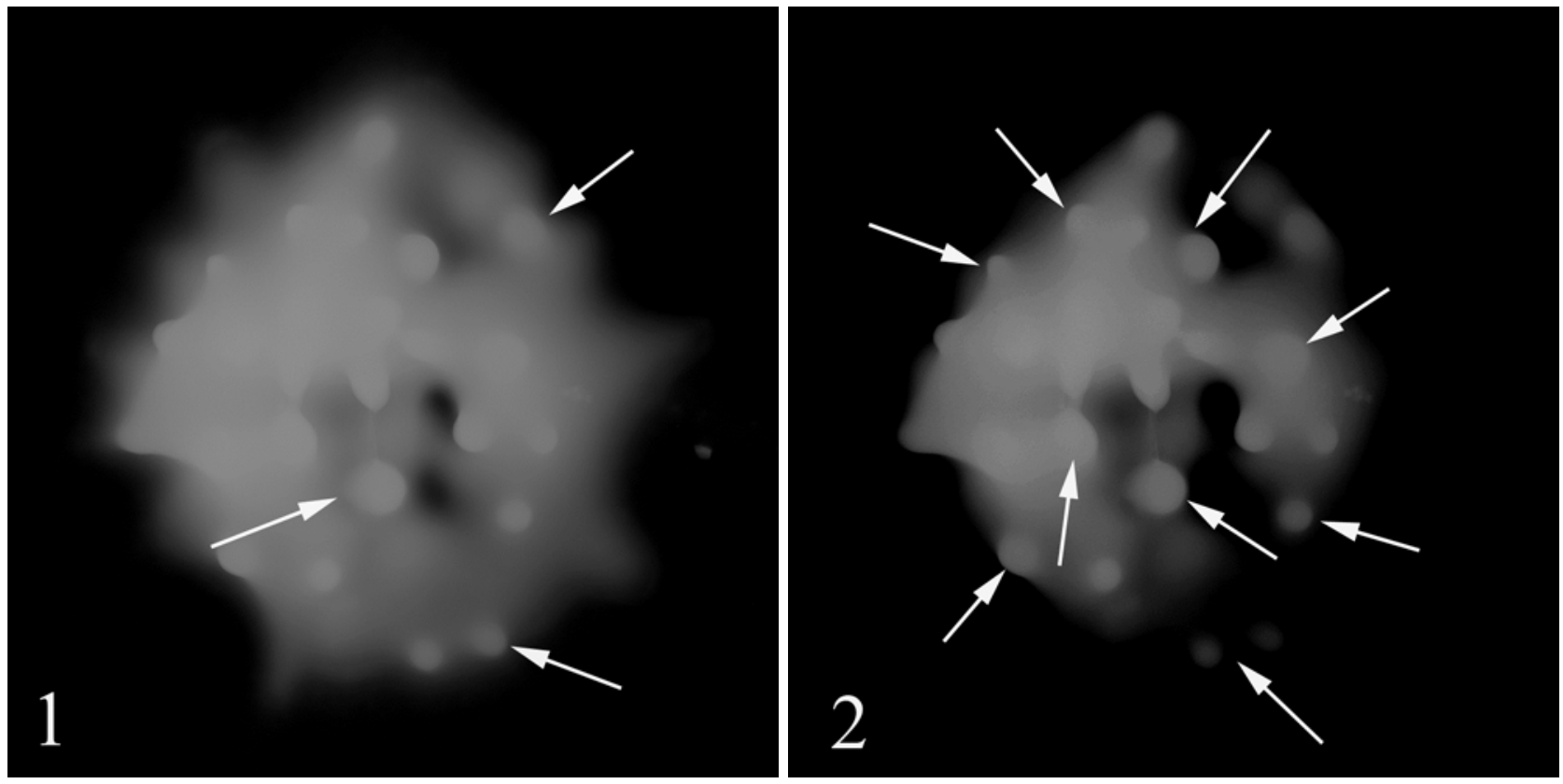

Fig.1 BE image of a hydrated platelet adhered to a silicon oxide partition membrane. Arrows indicate obvious dense granules (arrows). 25,000x

Fig.2 CL image of the same platelet. Note the numerous dense granules (arrows). Some of the cytoplasm is stained also. $25,000 \mathrm{x}$ 